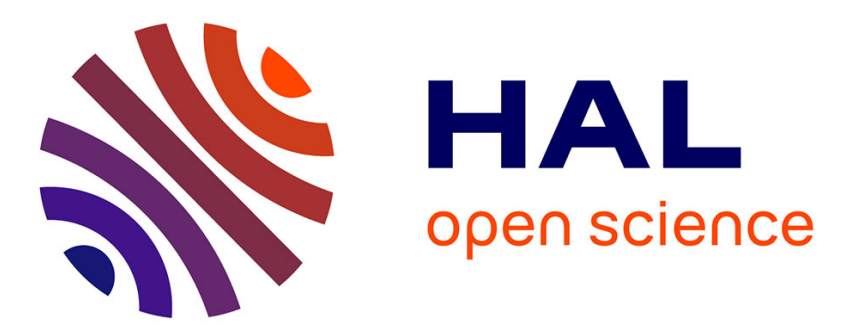

\title{
Taking into account emotions in mixed human/agent systems for improving collaborative work
}

Margaux Lhommet, Domitile Lourdeaux

\section{To cite this version:}

Margaux Lhommet, Domitile Lourdeaux. Taking into account emotions in mixed human/agent systems for improving collaborative work. International Symposium on the Management of Industrial and Corporate Knowledge, Jun 2011, Lausanne, Switzerland. pp.854 - 857, 10.1109/CSCWD.2011.5960218 . hal-00631069

\section{HAL Id: hal-00631069 \\ https://hal.science/hal-00631069}

Submitted on 11 Oct 2011

HAL is a multi-disciplinary open access archive for the deposit and dissemination of scientific research documents, whether they are published or not. The documents may come from teaching and research institutions in France or abroad, or from public or private research centers.
L'archive ouverte pluridisciplinaire HAL, est destinée au dépôt et à la diffusion de documents scientifiques de niveau recherche, publiés ou non, émanant des établissements d'enseignement et de recherche français ou étrangers, des laboratoires publics ou privés. 


\title{
Taking into account emotions in mixed human/agent systems for improving collaborative work
}

\author{
Margaux LHOMMET, Domitile LOURDEAUX \\ Laboratoire Heudiasyc \\ Université de Technologie de Compiègne \\ Compiègne, France \\ margaux.lhommet@hds.utc.fr; domitile.lourdeaux@hds.utc.fr
}

\begin{abstract}
Interacting with other persons implies having appropriate reactions to their actions. In the professional field, inappropriate responses can be very prejudicial. Many studies point out the importance of emotions in the construct of behavioral responses. This article proposes a model of emotional, social and cognitive Personal Assistant agent that can help its user to avoid conflicts.
\end{abstract}

Keywords-component; multi-agent systems; cognitive agent; emotion modeling

\section{INTRODUCTION}

Transferring knowledge results from a number of exchanges among a large number of persons involved in collaborative work. The behavior of each individual is influenced by the behavior of the others. If we assume that the process is mediated by a system of "intelligent" agents, then it would be interesting to take into account the various emotional states of the different actors.

Until now, doing so has not been considered mainly because modeling and handling emotions is a difficult problem and there was a lack of models for doing so. This paper presents a way of implementing emotional, social and cognitive agents, which could be an interesting addition in the context of multicultural interactions.

\section{MODELS OF EMOTION}

\section{A. Emotional contagion}

The construct of group emotion and shared emotion among group members has been broadened in recent years. Barsade [1] demonstrates the existence of emotional contagion among collaborative workers. She formulates some hypotheses that she validates with experiments: (1) There will be contagion of mood among group members. (2) Unpleasant emotions are more likely to lead to mood contagion than are pleasant emotions. (3) Positive emotional contagion will lead to greater cooperativeness, (4) to less group conflict, (5) and people will rate their own performance and that of others more highly.

From a broader point of view, emotional contagion between individuals is a long-time known phenomenon. In the first study concerning crowd and group behaviors published in 1895, Le Bon [2] (page 13) writes: "Contagion is a phenomenon of which it is easy to establish the presence, but

This research is financed by the Direction Générale de l'Armement, France. that it is not easy to explain. [...] In a crowd every sentiment and act is contagious, and contagious to such a degree that an individual readily sacrifices his personal interest to the collective interest."

Since then, several psychologist and sociologist studies have been focused of this phenomenon. In 1992, Hatfield et al. [3] (page 153) define emotional contagion as "the tendency to catch (experiencelexpress) another person's emotions (his or her emotional appraisals, subjective feelings, expressions, patterned physiological processes, action tendencies, and instrumental behaviors)."

\section{B. Emotions}

To date, there has been little agreement on what is an emotion. Most theorists would agree that emotion is a mental experience that motivates a reaction toward the initial stimuli. Usually, emotions are defined by common terms such as Joy, Distress, Fear, Hope, Pride...

Yet, we are here less interested in what emotions are than how they affect people's behavior. Since each person in the group is represented by her/his Personal Assistant (PA), emotions must be represented in a way that allows the PA to reason. Thus we focus on computational models of emotions.

The OCC emotional theory described by Ortony et al [4] specifies how events, other agent's actions and objects are confronted to the agent's desires, to its moral and cultural norms and to its preferences to generate an emotional state. It is widely used in the field of emotional agents because it determines the cognitive appraisal process in a straightforward way that favors implementation.

Lazarus [5] considers a two-steps emotional theory. The first step (cognitive appraisal) computes the agent's capacity to deal with the consequences of an event. In the second step (coping), if the event is stressful, the agent chooses a way to react to improve its situation. This reaction can whether be an action in the environment (problem-coping) or a new evaluation of its mental state (emotional-coping) such as denial or culpability. This theory is very complete and therefore, requires extensive computation. For this reason, it is very complex to implement and rarely used. 


\section{Computational model of emotional contagion}

Many studies investigating the contagion phenomenon have been carried out by biologist (such as contagious disease) and social scientists (such as rumors propagation and buyers or political tendencies). Dodds and Watts [6] identify two groups of contagion models. Those of independent interaction, used by mathematicians to represent infectious diseases' propagation, do not consider individual characteristics nor repeated expositions. Thresholds models, used in social contagion, define conditions that have to be fulfilled for the contagion to occur. Finally, all those models classify individuals in two groups depending on the fact that an individual is contaminated (and then contagious) or not.

Those studies are not compatible with the emotionalcontagion definition given by psychologists and sociologists: in the case of emotions, individual characteristics have a major importance on contagion and an individual is at each moment contaminated and contagious.

\section{AGENT MODEL}

Each individual interacts with the group via her/his PA. This PA is a cognitive, emotive and social autonomous agent that communicates and collaborates with the other workers' PA.

Figure 1 represents the global architecture of the PA.

\section{A. Personality}

Since the PA represents an individual, it must know how its user may react to certain events. Thus each PA has a personality model that represents the one of its user.

The two most important personality models are the threefactor model by Eysenck [7] and the five-factor model
(OCEAN) by Costa and McRae [8].

There are many questionnaires that allow to determine an user's personality in terms of OCEAN traits. This personality is static. Person A's personality is represented by the vector $\mathrm{P}(\mathrm{A})$ (1).

$$
\begin{gathered}
\mathrm{P}(A)=\left\{P_{O}, P_{C}, P_{E}, P_{A}, P_{N}\right\} \\
\forall i \in\{O, C, E, A, N\} P_{i} \in[-1,1]
\end{gathered}
$$

Table I describes with some adjectives each of the five factors of the OCEAN model.

TABLE I. OCEAN PERSONALITY TRAITS

\begin{tabular}{|c|l|l|}
\hline \multicolumn{1}{|c|}{ Traits } & \multicolumn{1}{|c|}{ Positive value } & \multicolumn{1}{c|}{ Negative value } \\
\hline $\begin{array}{c}\text { Openness to } \\
\text { Experience }\end{array}$ & $\begin{array}{l}\text { Curious, Imaginative, } \\
\text { Individualist }\end{array}$ & Conventional \\
\hline Consciousness & $\begin{array}{l}\text { Conscientious, } \\
\text { Organized }\end{array}$ & Impulsive, Distracted \\
\hline Extroversion & Gregarious, Enthusiastic & Not social \\
\hline Agreeableness & $\begin{array}{l}\text { Friendly, Popular, } \\
\text { Altruist, }\end{array}$ & Aggressive, Intransigent \\
\hline Neuroticism & $\begin{array}{l}\text { Emotionally stable, } \\
\text { Calm }\end{array}$ & $\begin{array}{l}\text { Anxious, Angry, Self- } \\
\text { conscious }\end{array}$ \\
\hline
\end{tabular}

\section{B. Relationship}

Collaborative working requires people to respect certain behavioral rules such as hierarchy respect, social norms and cultural standards. PA thus needs to have knowledge about the social relationship between its user and other co-workers. This relationship may concern affinity, hierarchy links, social or cultural norms. PA uses this relationship to determine supposed impacts of other worker's actions on its user.

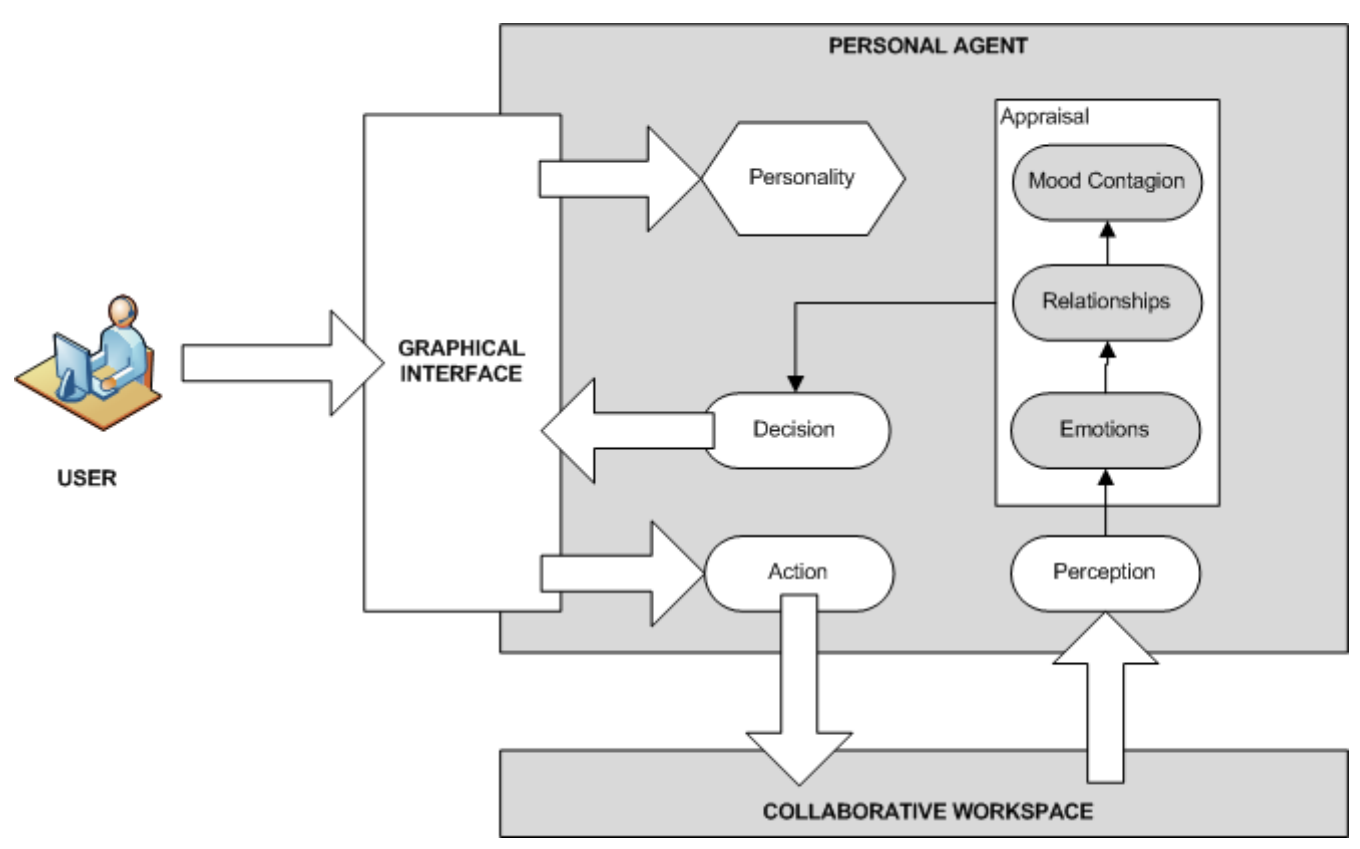

Figure 1. Architecture of the Personal Agent 
By way of illustration, if the agent A sees the agent B doing something it judges blameworthy (like being insolent to a superior), agent A's appreciation of agent B will be negatively impacted (as should be the supposed relationship between the two users).

The relationship of agent $A$ toward agent $B$ at time $t$ is represented by (2).

$$
\mathrm{R}_{A / B}(t)=i, i \in[-1,1]
$$

\section{Emotions and mood}

This paper uses the OCC emotional theory [4] that specifies how events, other agent actions and objects are confronted to the agent's goals (desires), standards (moral acceptability of actions) and attitudes (appealing of objects) to generate emotions.

While OCC theory defines 22 emotions (11 positive emotions and their opposite), our model only considers two which are Joy and its opposite Distress. We then define the emotional state Well-Being that represents the aggregation of those two opposite emotions; a negative value represents Distress whereas a positive value represents Joy.

Moods represent the current emotional state of the PA (the user's supposed emotional state). It is an aggregation over time of the successive emotional states of the PA.

\section{EMOTIONAL Module}

The emotional module is defined by two steps, the Event Appraisal and the Action Appraisal. They correspond to the OCC "Reactions to Events" and "Reactions to Agents " that respectively evaluates the impact of events and the impact of actions on the emotional state of the agent.

We draw a sharp distinction between the appraisal of events (Event Appraisal) and the appraisal of actions realized by other agents (Action Appraisal). In the first case, the module evaluates the impact of the event on the emotional state of the agent. In the second case, it evaluates the impact of the action on the relationship between the perceiver and the author of the action. Thus, an action is first evaluated by the Event Appraisal module to update the emotional state of the agent, then by the Action Appraisal module to update the relationship.

\section{A. Event Appraisal}

The OCC theory describes the processes used to appraise an event and issue an emotional state regarding to the agent's goals.

First, the desirability of the event is calculated. An event is said to be desirable (respectively undesirable) if it permits to increase (respectively decrease) the degree of achievement of one (or many) desire(s) of the agent.

Then, an emotion potential is computed for this event regarding its desirability (or undesirability).
It is not rare that many events occur at the same time, so those emotion potential are aggregated into a global emotional state that represents the instantaneous emotional state. Yet, the OCC theory provides no guidance about how to obtain a global emotional state from a set of potential emotions.

Egges [9] proposes a model based on matrices that represent the influence of personality traits on the aggregation of potential emotions into an emotional state.

Finally, mood is updated regarding its previous value and the new emotional state.

\section{B. Action Appraisal}

Action Appraisal module evaluates an action done by another agent. The OCC theory [4] (chapter 7) uses this evaluation to generate attribution emotions to the author of the action (such as anger or admiration) or to the perceiver itself (such as pride or shame). Since our model only defines WellBeing emotions, we directly use this appraisal to update the relationship between the perceiver and the actor.

Depending on the personality of the perceiver, the relationship may be impacted in different ways. For instance, an intransigent agent (with a low agreeableness value) will be less tolerant if an agent does an action its disapproves and the relationship between those two agents will be negatively impacted. In order to do so, we define a matrix that represents the impact of the personality on the evolution of the relationship.

\section{Emotional contagion}

So far, there is no emotional contagion model taking into account individual characteristics. However, researches and experiments have identified some individual differences that may influence emotional contagion. Hatfield et al. [10] point out that emotional contagion occurs between every individual, each being contaminated and contagious as the same time. For each individual, they also describe factors that influence the ability to infect others (Contagion Power or CP) and the susceptibility to be contaminated (Susceptibility to Contamination or SC).

An agent is more capable of transmitting its emotional state if it (1) feels strong emotions, (2) is able to express those strong emotions (facial, vocal, and/or postural expressions), (3) is relatively insensitive to the feeling of others when they are experiencing emotions incompatible with its own.

On the other hand, an agent may be more susceptible to be contaminated by others' emotions if it (1) is attentive to others, (2) considers itself related and dependent on others, (3) reads other's emotional expressions, voices, gestures and postures and tends to mimic them, (4) is aware of its own emotional responses, (5) is related to the other agent (involved in love or power relationship).

Indeed, those factors are generic and not directly usable. However, Hatfield et al. explain the behaviors associated with those factors well enough for us to propose a translation into our model of emotions (OCC), personality (OCEAN) and 
mood. Table II represents our interpretation of those descriptions.

Therefore, given its user personality, the PA can compute the Power of Contagion and Susceptibility to Contagion at each time regarding who interacts in the collaborative workspace.

\section{DISCUSSION}

We propose a model of cognitive, social and emotional agent. This agent can be implemented as a Personal Assistant for co-workers sharing a collaborative workspace. In this context, the PA must know its user personality and initial emotional state. Literature provides a lot of psychological tests that can be implemented to collect those values. The PA can then interpret the actions occurring on the collaborative workspace and adapt its behavior. This application could be useful in three ways:

Analysis: The system could compare the supposed emotional state of its user to its real one and then detect sudden change of mood.

Simulation: The system could simulate the occurrence of an event and its impact in the co-workers of the collaborative workspace.

Action: The system could act in many ways to avoid conflicts, such as tagging "bad mood" messages to alert the users or propose to reschedule meetings in case of a very tense situation.

Implementing emotions into Personal Assistants has not been considered yet, although many studies point out the importance of emotions in collaborate working. We provide a model of emotional, social and cognitive Personal Assistant that can act on the system and help the user to avoid conflicts.

TABLE II. EMOTIONAL CONTAGION MODEL

\begin{tabular}{|c|c|}
\hline Behavior & Interpretation \\
\hline \multicolumn{2}{|c|}{ Power of Contagion } \\
\hline Feel emotions & E- \\
\hline Express emotions & $\begin{array}{l}\mathrm{A}+(\text { charismatic }) \\
\mathrm{E}+, \mathrm{C}-\text { (impulsive) }\end{array}$ \\
\hline Insensitive to opposite emotions & $*$ \\
\hline \multicolumn{2}{|c|}{ Susceptibility to Contagion } \\
\hline Attentive to others & Mood + \\
\hline Dependent on others & $\mathrm{A}+, \mathrm{O}+$ \\
\hline $\begin{array}{l}\text { Read and mimic other's emotional } \\
\text { state }\end{array}$ & $\mathrm{A}+$ (friendly) \\
\hline Aware of emotions & $\mathrm{O}+$ (sensitive) \\
\hline Emotionally reactive & E- \\
\hline Love, admiration, respect & Relationship + \\
\hline
\end{tabular}

We hope that the model we are developing will help doing experimental work on the impact of emotional states on the quality of the transfer of knowledge among participants engaged in cooperative activities, either co-located or through distance work.

\section{REFERENCES}

[1] S. G Barsade, "The ripple effect: Emotional contagion in groups," Administrative Science Quarterly 47, n . 4 (2002): 664-675.

[2] Gustave Le Bon, Psychologie des foules, 1995 éd. (Paris: Presses Universitaires de France, 1895).

[3] E. Hatfield, J. T Cacioppo, et R. L Rapson, "Primitive emotional contagion.," Emotion and Social Behavior 14 (1992): 151-177.

[4] Andrew Ortony, Gerald L. Clore, et Allan Collins, The cognitive structure of emotions (Cambridge University Press, 1990).

[5] R. S Lazarus, Emotion and adaptation (Oxford University Press, USA, 1991).

[6] P. S Dodds et D. J Watts, "A generalized model of social and biological contagion," Journal of Theoretical Biology 232, n .4 (2005): 587-604.

[7] H. J Eysenck, "Biological dimensions of personality." (1990).

[8] P. T Costa, R. R McCrae, et Inc Psychological Assessment Resources, Revised NEO Personality Inventory (NEO PI-R) and Neo Five-Factor Inventory (NEO-FFI) (Psychological Assessment Resources Odessa, FL, 1992).

[9] A. Egges, S. Kshirsagar, et N. Magnenat-Thalmann, "Generic personality and emotion simulation for conversational agents," Computer Animation and Virtual Worlds 15, $\mathrm{n}^{\circ} .1$ (2004): 1-13.

[10] E. Hatfield, J. T Cacioppo, et R. L Rapson, Emotional contagion (Cambridge Univ Pr, 1994). 